\title{
APLIKASI LAMPU LED BERTENAGA SURYA SEBAGAI PENERANGAN RUMPON NELAYAN DI PANTAI ATAPUPU KABUPATEN BELU
}

Oleh:

\author{
Imanuel Chr. Mauko, ST., M.Eng * \\ Welem W. M. L Daga, ST., M.Eng *
}

\begin{abstract}
Abstrak
Pemakaian rumpon tradisional oleh nelayan di pesisir pantai Atapupu selama ini kurang efektif dalam hal memanggil ikan karena hanya menggunakan daun kelapa/daun lontar sebagai rumah ikan untuk berlindung dan mencari makan. Daun yang dipakai ini tidak bertahan lama karena rusak akibat gelombang maupun pembusukan daun dan juga waktu tangkap yang baik dan maksimal hanya terjadi pada saat subuh/remang-remang, dimana saat tersebut ikan tertarik untuk naik ke permukaan karena pantulan cahaya. Kurangnya pencahayaan dan mahalnya minyak tanah menyebabkan beberapa kelompok nelayan yang menggunakan rumpon enggan untuk menarik rumponnya diwaktu malam, padahal penarikan ikan saat malam menurut mereka lebih maksimal. Selain itu, kebutuhan minyak tanah untuk penerangan saat menarik rumpon ikan sekitar 5 liter atau setara Rp. 30.000,-

Untuk mengatasi masalah ini maka tim menerapkan penggunaan lampu LED bertenaga surya sebagai alat penerangan rumpon, sekaligus sebagai alat pemanggil ikan. Beberapa keunggulan lampu LED yang akan dirancang sebagai penerangan rumpon ini diantaranya dapat dicelupkan/direndam dalam air, lebih tahan lama, konsumsi daya listrik yang lebih sedikit dan dapat terdapat pilihan warna cahaya atau kerlap-kerlip yang cepat menarik perhatian ikan.

Penerapan teknologi penerangan rumpon dilakukan dengan merancang serta membuat suatu sistem penerangan menggunakan lampu LED dengan sumber tenaga berasal dari tenaga surya. Selanjutnya lampu penerangan ini digunakan pada saat penangkapan ikan dengan rumpon. Hasil penerapan teknologi lampu LED ini menunjukan adanya peningkatan hasil tangkapan ikan para nelayan pantai Atapupu yang pada akhirnya dapat meningkatan pendapatan dan ekonomi nelayan.
\end{abstract}

Kata Kunci: Rumpon Ikan, Lampu LED, Tenaga Surya

\section{Pendahuluan}

Penggunaan rumpon sebagai salah satu alat tangkap ikan telah banyak digunakan oleh nelayan di Indonesia. Keberadaan rumpon tradisional khususnya pada nelayan di Atapupu, Kab. Belu - NTT sampai dengan tahun 2010 tercatat hanya 23 buah rumpon yang efektif atau $\pm 11 \%$ dari total nelayan yang ada di wilayah Atapupu. Angka ini sangat kecil jika kita bandingkan dengan potensi wilayah pantai yang masih sangat luas untuk dijadikan lahan tangkap.

Pemakaian rumpon tradisional juga kurang efisien dalam hal memanggil ikan karena hanya menggunakan daun kelapa/daun lontar sebagai rumah ikan untuk berlindung dan mencari makan. Selain itu, daun yang dipakai ini tidak bertahan lama karena rusak akibat 
gelombang maupun pembusukan daun, waktu tangkap yang baik dan maksimal hanya terjadi pada saat subuh/remangremang, dimana saat tersebut ikan tertarik untuk naik ke permukaan karena pantulan cahaya. Kurangnya pencahayaan dan mahalnya minyak tanah menyebabkan beberapa kelompok nelayan yang menggunakan rumpon enggan untuk menarik rumponnya diwaktu malam, padahal penarikan ikan saat malam menurut mereka lebih maksimal. Selain itu, kebutuhan minyak tanah untuk penerangan saat menarik rumpon ikan sekitar 5 liter atau setara Rp. 30.000,-

Untuk mengatasi masalah ini maka tim menerapkan penggunaan lampu LED bertenaga surya sebagai alat penerangan rumpon, sekaligus sebagai alat pemanggil ikan.. Ini didasarkan atas keunggulan lampu LED diantaranya dapat dicelupkan/direndam dalam air, lebih tahan lama, konsumsi daya listrik yang lebih sedikit dan dapat terdapat pilihan warna cahaya atau kerlap-kerlip yang cepat menarik perhatian ikan. Melalui penerapan metode ini, diharapkan adanya peningkatan hasil produksi masyarakat nelayan di pesisir pantai Atapupu, Kabupaten Belu, Nusa Tenggara Timur.

\section{Metode Penyelesaian Masalah}

Kegiatan pengabdian pada masyarakat di pantai Atapupu dilakukan dalam beberapa metode diantaranya:

1. Memberikan penyuluhan kepada masyarakat nelayan di pesisir pantai Atapupu tentang pemanfaatan tenaga surya sebagai sumber daya listrik yang hemat energi dan ramah lingkungan.

2. Merancang serta membuat lampu LED bertenaga surya sebagai alat penerangan rumpon.

3. Memberikan pendampingan bagi kelompon nelayan pengguna teknologi lampu LED bertenaga surya sekaligus pendampingan, pemantauan dan evaluasi terhadap efektifitas dan efisiensi alat tersebut.

\section{Hasil dan Pembahasan}

\section{A. Tahap Persiapan Alat dan Bahan}

Persiapan alat dan bahan juga dilakukan di 2 lokasi terpisah secara bersamaan. Di Kupang, persiapan alat dan bahan yang dilakukan berhubungan dengan pembuatan sistem lampu LED bertenaga surya, sedangkan di Pantai Atapupu, persiapan dilakukan terutama pembuatan jangkar rumpon dan perakitan rumpon ikan. Alat dan bahan yang digunakan dalam pembuatan lampu LED bertenaga surya diantaranya: Panel Surya, Aki 12 V/70 Amper, lampu LED $6 \times 1$, lembaran karet, Alumunium Foil, double tip, lem, kabel, pisau cutter, gunting, Multimeter, dan aksesoris lainnya. Sedangkan alat dan bahan pembuatan rumpun ikan meliputi drum fiber untuk badan rumpon dan drum bekas aspal untuk jangkar rumpon dan bahan lain seperti pasir, semen, kerikul, besi beton, tali nilon $16 \mathrm{~mm}$ dan besi sambungan (kili-kili).
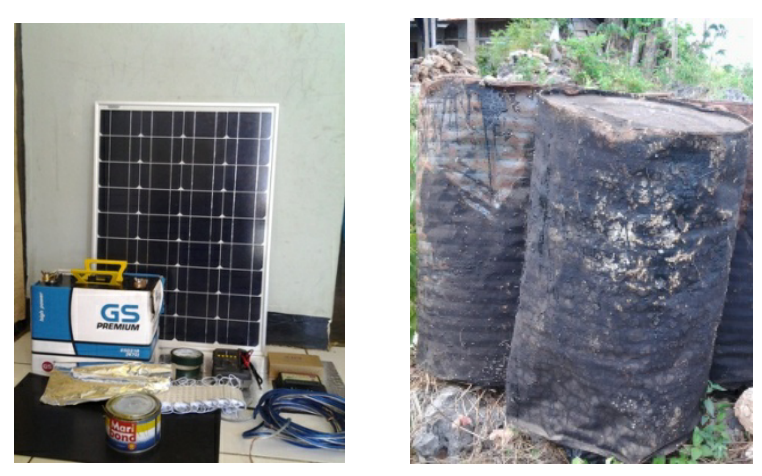

Gambar 1. Persiapan Alat dan Bahan embuatan Lampu Rumpon

\section{B. Tahap Pembuatan Alat}

1. Pembuatan Lampu LED

Pembuatan lampu LED menggunakan alat dan bahan yang sudah dipersiapkan. Hasil Pembuatan lampu seperti ditunjukkan pada gambar 1. Lampu LED 
yang dibuat merupakan lampu LED yang hemat energi, memiliki umur pemakaian yang lama serta tahan air sehingga dapat dimasukan kedalam laut untuk menarik ikan

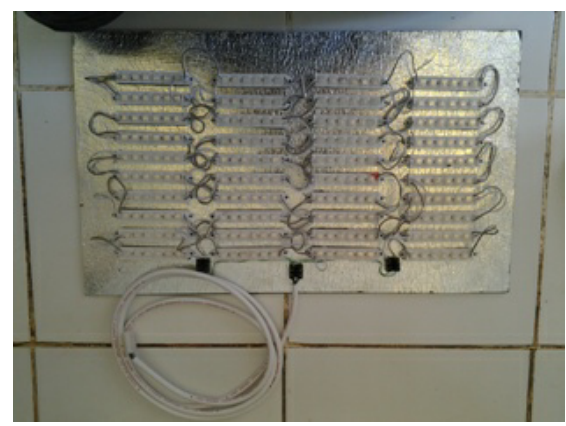

Gambar 2. Modul Lampu LED yang Siap digunakan

2. Perancangan Sistem Sel Surya Sistem penerangan menggunakan LED tenaga surya menggunakan sel surya sebagai sumber energi. Pemakaian sel surya sebagai salah satu bentuk penghematan bahan bakar minyak yang sudah mulai langka serta mahal harganya. Sistem sel surya yang dibangun terdiri dari panel surya ukuran 50WP, sebuah kontroler PWM 12/24 Volt 20 Ampere serta sebuah Aki 70 Amper sebagai penampung Arus. Sistem sel surya dengan rangkaian lampu terpasang seperti pada gambar 3 .

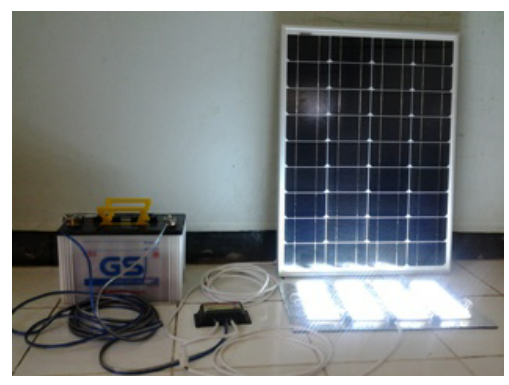

Gambar 3. Sistem Penerangan Sel Surya
3. Pembuatan Rumpon Ikan

Pembuatan rumpon ikan sebagai alat penangkapan ikan terdiri dari pelampung rumpon dan jangkar rumpon. Pelampung rumpon dibuat menggunakan drum plastik sebanyak 2 buah dan diikat dengan menggunakan tali nilon $16 \mathrm{~mm}$, sedangkan jangkarnya terbuat dari drum bekas aspal yang dicor sehingga dapat digunakan sebagai penambat rumpon di laut agar tidak mudah terseret arus. Hasil pembuatan pelampung rumpon dan jangkar rumpon seperti pada gambar 4.
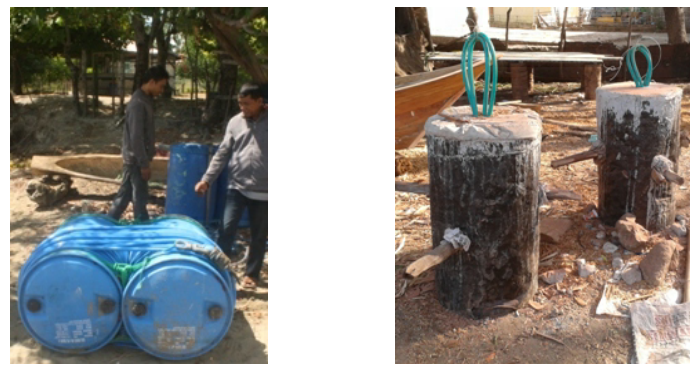

$\begin{array}{ll}\text { (a) Badan Rumpon } & \text { (b) Jangkar Rumpon }\end{array}$ Gambar 4. Hasil Pembuatan Rumpon Ikan

\section{Tahap Aplikasi Teknologi Penerangan Rumpon Menggunakan LED Tenaga Surya}

Setelah semua komponen sistem penerangan rumpon ini dibuat, selanjutnya adalah dengan merakitnya menjadi satu kesatuan fungsi sehingga nantinya dapat digunakan oleh kelompok nelayan di pesisir pantai Atapupu. Hasil uji coba aplikasi peralatan seperti ditunjukkan pada gambar 5. Dalam tahap uji coba ini akan dilihat seberapa besar pengaruh lampu yang dibuat terhadap ketertarikan ikan untuk datang berkumpul di sekitar rumpon. Proses ini dapat memakan waktu kurang lebih 
1 sampai 2 bulan. Hasil pemantauan dilaporkan dalam bentuk tabel seperti di bawah ini:

Tabel 1. Evaluasi Pemakaian Lampu

\begin{tabular}{|l|l|l|l|l|}
\hline N & Indikator & \multicolumn{2}{|l|}{ Kondisi Nelayan } & \multirow{2}{*}{ i } \\
\cline { 3 - 4 } & & $\begin{array}{l}\text { Sebelum } \\
\text { Penerapan } \\
\text { Lampu } \\
\text { Rumpon }\end{array}$ & $\begin{array}{l}\text { Setelah } \\
\text { Penerapa } \\
\text { n Lampu } \\
\text { Rumpon }\end{array}$ & \\
\hline 1 & $\begin{array}{l}\text { Pemakai } \\
\text { an BBM }\end{array}$ & 5 Liter/hari & - & Baik \\
\hline 2 & $\begin{array}{l}\text { Jumlah } \\
\text { Konsetra } \\
\text { si ikan }\end{array}$ & $\begin{array}{l}\text { Sedikit dan } \\
\text { tidak tahan } \\
\text { lama }\end{array}$ & $\begin{array}{l}\text { Lebih } \\
\text { banyak } \\
\text { dan tahan } \\
\text { lama }\end{array}$ & Baik \\
\hline 3 & $\begin{array}{l}\text { Hasil } \\
\text { Tangkap } \\
\text { an } \\
\text { Nelayan }\end{array}$ & Sedikit & $\begin{array}{l}\text { Lebih } \\
\text { Banyak }\end{array}$ & Baik \\
\hline
\end{tabular}

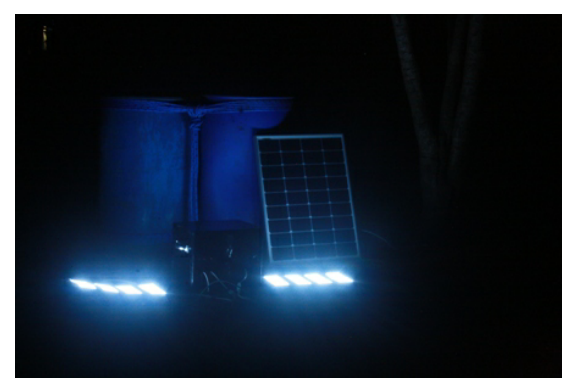

Gambar 5. Uji Coba Penerapan Lampu Rumpon

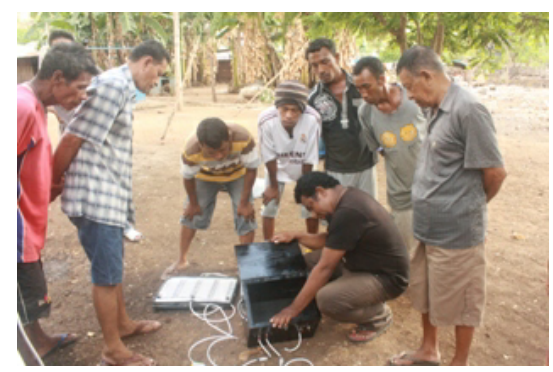

Gambar 6. Penyuluhan dan Pelatihan Cara Pengunaan dan Pemeliharaan Lampu

\section{A. Tahap Evaluasi dan \\ Pendampingan Berkelanjutan}

Setelah semua tahapan dilakukan, yang paling akhir dilakukan adalah melakukan pemantauan dan evaluasi serta pendampingan berkelanjutan agar penerapan lampu rumpon menggunakan LED bertenaga surya ini benar-benar memberikan dampak yang besar terhadap hasil tangkapan nelayan. Hasil tangkapan saat menggunakan rumpon memperlihatkan bahwa jumlah ikan terkonsentrasi di rumpon mengalami peningkatan yang signifikan. Menurut koordinator nelayan di pantai Atapupu, bahwa hasil tangkapan lebih banyak daripada menggunakan penerangan tradisional yakni mendekati dua kali lipat dari tangkapan biasanya. Efek lain dari penggunaan lampu LED ini adalah bahwa ikan terkonsentrasi lebih banyak dan lebih lama dari biasanya. Perhitungan ekonomis juga menunjukan pendapatan nelayan mengalami peningkatan akibat adanya peningkatan hasil tangkapan ikan. Dari hasil tangkapan yang ada, kelompok nelayan purnama menjualnya dan memperoleh pendapatan sebesar kurang lebih Rp. 3.500.000,-. Hasil ini lebih banyak dari biasanya yakni berkisar Rp. 1.000.000,hingga Rp 2.000.000 dalam sekali menarik rumpon. Ditinjau dari segi pemakaian bahan bakar juga masih menguntungkan nelayan karena tidak menggunakan bahan bakar minyak sebagai sumber energi penerangan rumpon.

Dari hasil evaluasi terhadap implementasi peralatan dapat disimpulkan bahwa dengan penerapan lampu penerangan rumpon menggunakan LED bertenaga surya yang hemat energi dan ramah lingkungan ini, dapat meningkatkan hasil tangkapan nelayan serta mempertahankan wilayah konsentrasi ikan di 
perairan Atapupu yang pada gilirannya dapat meningkatkan pendapatan kelompok nelayan. Selanjutnya, akan dilakukan pendampngan berkelanjutan dalam jangka waktu kurang lebih 6 bulan kedepan untuk melihat lebih detail efek pemanfaatan lampu penerangan rumpon menggunakan LED bertenaga surya ini. Selain itu juga akan diujicobakan variasi warna lampu LED untuk pemanggil ikan tertentu sehingga pemanfaatan lampu rumpon ini benar-benar dapat dimaksimalkan.Selain itu juga, dilakukan beberapa uji coba pemakaian lampu dengan warna yang berbeda untuk menarik minat ikan tertentu serta variasi kedalaman lampu untuk mengetahui seberapa besar efek lampu rumpon tersebut terhadap daya tarik ikan. Semua proses ini dilakukan dalam jangka waktu yang panjang hingga kurang lebih 6 bulan.

\section{KESIMPULAN DAN SARAN}

\section{A. Kesimpulan}

Dari uraian di atas, dapat disimpulkan:

1. Lampu penerangan rumpon yang hemat energi dan ramah lingkungan dapat dibuat menggunakan lampu LED dengan sistem sel surya.

2. Penerapan lampu LED bertenaga surya ini dapat meningkatkan jumlah konsentrasi ikan pada rumpon yang pada gilirannya meningkatkan hasil tangkapan nelayan serta berdampak secara langsung pada peningkatan ekonomi kelompok nelayan di pesisir pantai Atapupu, Kabupaten Belu.

\section{B. Saran}

1. Pemakaian lampu rumpon hendaknya mengikuti petunjuk penggunakan serta pemeliharaan yang baik sehingga dapat tahan lama.

2. Untuk pemakaian pada laut yang dalam, lampu LED perlu didesain agar tahan terhadap tekanan air laut.

\section{DAFTAR PUSTAKA}

Jamal, M., 2003. Studi Pengguaan Rumpon untuk Meningkatkan Produksi Hasil Tangkapan gillnet dan Bubu Dasar yang dioperasikan di Perairan Kabupaten Sinjai Sulawesi Selatan. Lutjanus. Jurnal Teknologi Perikanan dan Kelautan. Vol 8 No.2, Juli 2003, hal 223-231.

Dahuri, R. 2003. Paradigma Baru Pembangunan Indonesia Berbasis Kelautan.Orasi Ilmiah Guru Besar Tetap Bidang Pengelolaan Sumberdaya Pesisir dan Lautan. Institut Pertanian Bogor, Bogor, 2003

Subani, W. 1986. Telaah Penggunaan Rumpon dan Payaos dalam Perikanan Indonesia Jurnal Penelitian Perikanan Laut, BPPL, Jakarta, 35: 35-45.

Monintja D.R., 1993. Study on development of rumpon as Fish Aggregating Devices. Mar. Technol. Bull. ITK, 3(3), 1-1.37. 
